\title{
MASIFICACIÓN DEL CONSUMO DE TECNOLOGÍAS \\ PARA EL DESARROLLO RURAL: \\ Evolución en la Revolución Tecnológica Agropecuaria
}

Joseph Malta ${ }^{1}$

\section{1.- INTRODUCCIÓN: ¿QUÉ ES LA TECNOLOGÍA?}

\section{1.- ¿Productividad versus Progreso?}

Empiezo sugiriendo que para que la política pública y la política de desarrollo rural funcionen bien, es necesario escaparse de la abstracción de la maximización de beneficios. En esto, lo más complicado es la dependencia tecnológica, y le sumo, revertir la mirada desde los intereses externos a lo interno: siempre, ya sea en sustitución de importaciones (protección de los capitales nacionales) o promoción de exportaciones (campo abierto para los mega capitales), la mirada ha estado en lo externo; allá está la tecnología y el conocimiento, y ellos también son el mercado. De aquí surgen dos conclusiones no tan halagadoras, que paradójicamente confluyen entre sí: optamos por una única tecnología; mientras que el conocimiento local dejó de tenerse en cuenta.

Así, pareciera ser que la tecnología es: la relación de las cantidades de factores con las cantidades de producto: si aumenta la cantidad de producto que puede generar un conjunto dado de factores, entonces los costos de producción disminuyen. Y esto se ha impuesto como progreso tecnológico.

Tal idea se ha masificado en todos los campos de las ciencias, por ejemplo, la noción ingenieril es exacta y sin ambigüedades: dividiendo el trabajo realizado entre las horas

\footnotetext{
${ }^{1}$ Profesor Titular III, UNAH. Asistente de la Coordinación de la División de Tecnología Educativa de la Dirección de Educación Superior. Miembro del Grupo Gestor del Plan de Sostenibilidad de Iniciativas y Redes de Derechos Humanos en Honduras, con Visión Regional Centroamericana: 2010 - 2015 (UNAH UPNFM - CIPRODEH).
} 
empleadas se determina la productividad promedio para cada actividad. Pudiéramos agregar otras variables para abundar en el concepto de tecnología, pero realmente no parecen ser suficientes para una noción que priorice la vida, la familia, la comunidad, lo endógeno, lo regional, el Estado - Nación. Otras variables de esa noción insuficiente, instrumental y abstracta de la tecnología, son las siguientes:

- Condiciones Meteorológicas

- Métodos de Operación

- Utilización del Equipo

- Mantenimiento Preventivo

$\Rightarrow$ Eficiencia del Operador

- Duración del Turno

- Efecto de la Curva de Aprendizaje

- Restricciones de la Fuerza de Trabajo

- Rotación de la Fuerza de Trabajo

- Costo de la Supervisión

La programación y valoración del trabajo que sería como influir en una mejor condición de vida, es un examen de la influencia de las variables sobre la productividad.

Tenemos que empezar a ver, construir, razonar, decidir y hacer de forma diferente. Teniendo una aproximación a los planteamientos de Joan Robinson se ve una trascendencia que viene de insistir en las variables abstractas y la máquina, a reconocer al hombre como el medio por el cual resultan los productos, ya sea en su nivel de apropiación o de transformación de la naturaleza. La capacidad productiva se define como el producto por hombre y hora de un equipo de hombres que trabajan con máquinas.

\section{2.- ¿Cambio Tecnológico Inducido?}

No ha habido cambio sin motivación aparente. La tasa de innovación es motivada por incentivos económicos (la ganancia). De modo que el nivel de tecnología más ha sido una decisión empresarial y muy poco con visión de nación. Por aquí puede estar la clave 
de lo que se requiere hacer y surgen preguntas, tales como: ¿a quién favorece el Estado con sus innovaciones tecnológicas?, ¿deberíamos creer que la fuerza empresarial invierte en tecnología?, y ¿quién es considerado empresario?, ¿por qué se confunde a los empresarios con los privados?, ¿por qué se asume que todos los privados tienen cierto nivel de desarrollo?,... ¿pueden los pequeños invertir? ¿Es factible un mercado de tecnologías?

Estas preguntas no tienen respuestas únicas. Nos detenemos en esta última y repreguntamos - por decir algo- ¿las patentes y los derechos de propiedad son para promover la innovación o la exclusión? Es necesario poner salvaguardas, es necesario mejorar las condiciones de los mercados de tecnologías. Los pequeños pudieran perfectamente acceder al mercado de tecnologías y hasta generar tecnologías; el proceder a este punto ya no es por medio de criterios técnicos sino mediante decisiones de política económica, de innovación tecnológica, agroindustrial y agropecuaria.

Estas preguntas en países desarrollados probablemente tienen la respuesta más clara, pero en países subdesarrollados y de dependencia tecnológica, aún los criterios de ciencia tendrían sus variantes en lo que respecta al campo de la aplicación del instrumental tecnológico...

\section{3.- ¿Cambiar la Psicología de Adopción de Tecnologías?}

Hay al menos tres caminos a seguir en la adopción de tecnologías.

a. Adoptar las invenciones ya logradas.

b. Idear sus propios perfeccionamientos en Departamentos de Investigación.

c. Adueñarse de los experimentos de audaces investigadores y productores.

La primera modalidad está referida a dotación y/o aceptación de tecnologías foráneas, la segunda es innovación y creatividad propia (poco practicada), y la tercera es abusar del conocimiento de otros (del conocimiento local). 
Dónde haya posibilidades de generar un mercado de tecnologías, entonces se trabaja con los más innovadores mediante patentes u otros mecanismos que mantienen en secreto el procedimiento o legitiman la propiedad de la invención. Una vez que los compradores y los seguidores adquieren las nuevas tecnologías, los innovadores se aventuran a algo nuevo.

Visto así, pareciera un proceso de acelerado crecimiento y con sostenibilidad; no obstante la práctica indica que lo que se profundiza son los niveles de dependencia tecnológica externa; siguiendo criterios de economía subsidiaria, aún los grandes están a la espera de las ofertas de las instituciones tecnológicas de Estado; la masificación de las tecnologías no opera porque los experimentos y validaciones no tienen en cuenta las condiciones sociales, organizativas, ambientales y económicas de producción; hay un descartar del conocimiento local. A fin de mejorar estos criterios es necesario cambiar la filosofía imperante de generación y transferencia de tecnología.

\section{4.- ¿Es Momento del Cambio Tecnológico?}

Según Joan Robinson, de-constructora y constructora de la Teoría Schumpeteriana, siempre es momento del cambio tecnológico, y no necesariamente es un proceso de maduración en el tiempo, pues, la inventiva tiene que ser la constante del sistema económico y del proceso de producción:

El proceso de acumulación de la capacidad productiva tiene lugar en el seno de un huracán de destrucción creadora (argumento central de Schumpeter).

Lo que indica que hay que cambiar de tecnología. Según Robinson debemos verificar tres elementos del cambio tecnológico y es su propio distanciamiento de Schumpeter:

\section{a.- Acumulación Neutra u Orientada:}

En general, la nueva tecnología puede inclinar la demanda a favor de la fuerza de trabajo corriente o a favor del equipamiento, en comparación con la tecnología que está siendo desplazada (el riesgo de siempre advertido por Joan Robinson). 
Cualquiera que sea la inclinación, ya no es posible aducir que hay neutralidad. Si se trata de equiparar entre hombres y máquinas, el hombre debería ser el interés primordial.

Cada cambio tecnológico, cada invención debe compararse con determinado nivel de acumulación requerida la cual debe ser superada, de lo contrario la ciencia (cercana al mercado) no registra los respectivos valores de uso; otra opción puede ser la masificación de las tecnologías, misma que debe verse compensada y/o justificada por los procesos de acumulación. El mejor y complicado escenario sería que las tecnologías son para todos, constituyéndose en el principal reto de la política de desarrollo rural endógeno.

\section{b.- La Inestabilidad Vía el Ciclo Económico:}

Schumpeter argüía que las variaciones en la tasa de cambio técnico son suficientes para explicar las fluctuaciones históricamente observadas en la actividad de la industria capitalista conocida como el ciclo comercial (Crítica de Joan Robinson al simplismo Shumpeteriano).

Otra tesis es que, el sistema capitalista tiene tales contradicciones, que confronta a sus actores, y entonces padece crisis recurrentes. También, se dice que las fuerzas productivas se revolucionan de tal modo que es necesario cambiar hacia otro sistema (se obvia que el mismo sistema puede mutarse).

En nuestros sitios pobres, o bien no se genera la revolución de las fuerzas productivas y tampoco se promueven estas finalidades. Lo que más procede es depender de otros niveles: nivel de dependencia tecnológica de las instituciones internacionales agrícolas, nivel de dependencia de las instituciones tecnológicas estatales, nivel de dependencia de... Al final puede pasar que mejor en superficialidad pero peor en profundidad del mercado, se suma la expectativa de generar un mercado de tecnologías donde no se demandan tecnologías y quizá el elemento más impactante y apropiado sería la estrategia de dotación de tecnologías por vías extra mercado. Además, no se le ha puesto atención a un fenómeno 
que ya es evidente: “en los pequeños -más que las tecnologías-, están ejerciendo sobre ellos un impacto favorable, los mecanismos de asociativismo, cooperativismo y trabajo agremiado".

\section{c.- Elementos de la Acumulación:}

La inversión debe renovarse, los equipos no son eternos; en todo momento se requiere pasar de equipos viejos a nuevos y de una línea a otra. Se necesita en todos los sentidos un nivel productivo más alto, y debe resaltar el elemento educativo. Es necesario un sistema estatal de adiestramiento.

\section{5.- ¿La Razón del Cambio Tecnológico?}

El cambio técnico afecta el carácter de las mercancías que se producen, así como los métodos de producirlas. Los nuevos métodos de producción influyen en el carácter de los productos, y los nuevos productos se inventan para aprovechar a los nuevos métodos. De la búsqueda de la ganancia, el impacto último debe variar hacia manifestarse en una mejoría en la calidad de vida: debe mejorar la mayoría de ciudadanos, las comunidades rurales, las familias, y los productores ${ }^{2}$.

Se tienen que ir reconociendo otras formas de ver mejor la abstracción tecnológica. En la vida, todos los fenómenos sociales se condicionan mutuamente y se hallan concatenados. Por lo cual se hace importante un complejo económico interconexo...

Esto reafirma que la tecnología no debe ser en sí misma, sino base firme para el mejoramiento de las condiciones de vida de los trabajadores y la elevación de su nivel cultural: aumento de salario mínimo, crecimiento de ingresos, fondos sociales de consumo y comercio al por menor, ampliación de construcción de viviendas, se perfecciona el sistema de instrucción pública y sanidad, progresa la ciencia y la cultura, la unidad política e ideológica, y la amistad entre las naciones ${ }^{3}$.

\footnotetext{
${ }^{2}$ Tomado de "La creación de la base material y técnica del comunismo" 219 y 220.

${ }^{3}$ Idem, cita anterior, 219 y 220.
} 
Un elemento que no debe obviarse es lo internacional del problema. Encontramos de nuevo que la tecnología es un asunto de internacionales, es algo de ribete mundial: el llamado "Saber" a disposición de quién ha estado y a disposición de quién debe seguir (por lo tanto no es cierto que sea una discusión técnica y neutral); si hasta ahora hemos ganado, debería estar reflejado en la calidad de -la vida misma-, ese es el parámetro inclaudicable de medición. Ha sido claro lo que se requiere de estas tecnologías, lo que no ha estado bien consumado es qué tipo, a quién beneficiar, y más allá el razonamiento de lo que esto implica para el ambiente.

\section{2.- EPISTEMOLOGÍA DE LA TECNOLOGÍA: HACIA UN NUEVO PARADIGMA TECNOLÓGICO}

\section{1.- Ciencia, Tecnología y Sociedad: Más sobre el Paradigma de Occidente ${ }^{4}$}

Para Edgar Morin, desde sus nociones epistemológicas-filosóficas, la ciencia es poder de apresamiento y de manipulación. La tónica "científica" es divide y vencerás. Morin acusa que no hay tal naturaleza de los avances científicos, sino van siendo moldeados en respuesta a un modelo de vida imperante: El Paradigma de Occidente (aquella noción trillada de un modelo de desarrollo único, tecnológico, de mercados, de grandes ciudades; sin importar en qué escala se desenvuelvan los relacionamientos humanos).

La fórmula científica de la cual Morin se hace a un lado es la siguiente:

- La de Maquiavelo para dominar la ciudad.

- La de Descartes para dominar la dificultad intelectual.

- La de Taylor para regir las operaciones del trabajador en la empresa.

- La de Smith para embaucarnos de que el egoísmo es lo que debe primar.

$\Rightarrow \quad$ La de Keynes para generarle demanda efectiva y movilidad a las empresas vía auxilio estatal.

- La de Friedman para la liberación comercial a un alto costo social (para él eso es la democracia económica, la "libertad de elegir").

\footnotetext{
${ }^{4}$ Para saber más y profundizar: Ver E. Morin, El Método, IV Cátedra.
} 
- La máxima común se ramifica en la política, la cultura, el pensamiento, la sociedad.

En consecuencia, la ciencia debe evolucionarse y revolucionarse.... al servicio de las grandes mayorías, y siempre hay posibilidad de hacer las cosas diferentes, no vale una ciencia conservadora, una ciencia regalada; deben revestirse los esfuerzos locales, debe revestirse la forma de hacer ciencia, deben cambiarse los niveles de dependencia tecnológica (Precepto General de Denis Goulett); el reto es el lado de la libertad que brinda la ciencia...

El paradigma de occidente reina dividiendo. Es diabólico, es decir separador. Pero está compensado por las dialógicas y recursivas del proceso histórico (Profundizar en Goulett ${ }^{5}$ 233).

Se observa que la ciencia va manipulando para verificar y la técnica verificando para manipular. En este sentido la tecno ciencia toma posesión de la sociedad, cuando lo que se requiere es que la sociedad se apropie de la tecno ciencia y la destruya, que los esfuerzos sean para el desarrollo efectivo de la sociedad, en medio de nuevos conceptos y roles de las universidades, empresas industriales, sector agropecuario y el Estado. Todo esto significa cambiar la noción de búsqueda de la eficacia a cualquier precio: la ciencia, la técnica, la innovación deben dejar la periferia de sus transformaciones y llegar al corazón de la sociedad.

\section{2.- La Tecnología y la Ideología ${ }^{6}$}

Para algunos técnicos (y no digamos para muchos por ser optimistas) resolver las demandas puntuales del agro no es tan interesante como sí lo sería guiarse por megaproyectos, visiones y nociones amplias, conglomerados y otros. Desprecian al pequeño productor, al pobre rural; penalizan la promotoría, la banca de fomento, la participación ciudadana y la democracia directa en la nueva ruralidad. Todo esto lo ven como una politización, y se

\footnotetext{
${ }^{5}$ Denis Goulet; Ética del Desarrollo: Guía Teórica y Práctica. Universidad de Notre Dame.

${ }^{6}$ Este acápite se ha nutrido de Augusto Serrano, Introducción a la Epistemología.
} 
apuntan en la mera tecnocracia. Ignoran que también es politización el arraigo ciego a la competitividad, productividad, crecimiento, los mercados, la exportación, entre otros.

Otros técnicos reconocen dos corrientes y se apresuran a ubicarse en una $\mathrm{u}$ otra: la agricultura conservacionista o en la corriente del crecimiento sin límites. Cualquiera que sea pasa por una decisión política que en primera instancia esconde la verdadera realidad de las comunidades rurales.

A decir verdad, la ideología siempre está presente. Un buen extracto de lo que queremos decir lo encontramos en Augusto Serrano (economista y filósofo español):

La ideología es, pues, discurso, organización determinada y trabazón de ideas. No simplemente conjunto de ideas. Pero es discurso "necesitante", es decir, forma de la conciencia social que presenta lo contingente como lo necesario a partir de unos fines deseados o imaginados. La ideología no sólo es conjunto de ideas.

Entonces, cuando alguien habla del fin de las ideologías (como Noam Schomski) se las ve como algo corriente, como mero discurso, diatribas discusiones y retórica sin fin. No son ciertas las tales ciencias puras; en todo se encuentra un mensaje ideológico entre líneas. Cuando se favorece a unos y no a otros, de cualquier lado, pasa por una decisión ideológica. Queda la tarea de averiguar por donde andan las preferencias según las relaciones de fuerza del contexto imperante. ¿Qué preferimos en términos de gestión y transferencia tecnológica?:

\begin{tabular}{|c|c|c|}
\hline COMPONENTE & $\begin{array}{l}\text { Enfoque imperante (como } \\
\text { sea ha fracasado) }\end{array}$ & $\begin{array}{l}\text { Enfoque de cambio } \\
\text { (para unos es avance y } \\
\text { para otros retroceso - } \\
\text { todavía no ha triunfado) }\end{array}$ \\
\hline Investigación & $\begin{array}{ll}\text { Desarrollo } & \text { de } \\
\text { Conglomerados } & \end{array}$ & $\begin{array}{l}\text { Cooperativas } \\
\text { Asociaciones }\end{array}$ \\
\hline Extensión & $\begin{array}{l}\text { Empresas y Mercados de } \\
\text { Servicios de Extensión }\end{array}$ & Promotoría Rural \\
\hline Capacitación & Destrezas de Mercado & $\begin{array}{l}\text { Gestión del Desarrollo } \\
\text { Humano. Enfoque Integral }\end{array}$ \\
\hline Innovación & Paquetes Tecnológicos & Tecnología Apropiada \\
\hline
\end{tabular}


Siendo que la tecnología está preñada de ideología, es imperante que la entendamos de la siguiente forma: $\underline{\operatorname{La~tecnologí}}^{7}$ no es una cosa como cualquier otra que puede escogerse al libre albedrío; la tecnología vehicula y canaliza muchos de los valores de su sociedad, su matriz de origen. Son sesgos a favor (o deben serlo) de las inclinaciones propias de cada región, sus matices, sus costumbres, etc...

Así nos sumamos a las conclusiones de Serrano:

- La ideología da fuerza y consistencia a la ciencia; la ideología está acompañada del error y del fracaso.

- La meta es un camino previo, recorrido por la conciencia.

- La superestructura no es la determinante; en la estructura es donde se rescata la esencia de las tecnologías.

De lo primero podemos decir, que una política por muy bien intencionada no asegura el bienestar; de lo segundo, que aunque las metas se maticen metodológicamente, nunca se desentienden de la intenciones preconcebidas; de lo tercero, que la discusión no es donde se deciden las ideologías, las tecnologías o la política, sino donde se buscan los resultados de la misma.

\section{3.- La Racionalidad Tecnológica de la Sinrazón y la Esclavitud ${ }^{8}$}

Herbert Marcuse hace un llamado a buscar la esencia de las cosas, contrapuesto al mundo de la superficialidad: La esencia es posible encontrarla. Las cosas no son lo que son, sino lo que deben ser. Este cientista asume responsabilidades de cambio, alienta a que las cosas pueden ser diferentes y es en la esencia del hombre donde radica el poder subversivo. El hombre cuando se doblega ante la tecnología ya no tiene posibilidades de realizarse, en

\footnotetext{
${ }^{7}$ Tomado de POSCAE. Postgrado Centroamericano en Economía y Desarrollo. Revista Centroamericana de Economía. Artículo de Joseph Malta: Insumos para el Desarrollo. II Época, Mayo - Diciembre 1999, Año 5, No. 55 y 56. Universidad Nacional Autónoma de Honduras.

8 Ampliar en Herbert Marcuse.-la racionalidad tecnológica y la lógica de la dominación.- El hombre unidimensional, Beacon Press, 1964
} 
consecuencia no puede ser la tecnología lo imperante; estas nunca deben ser más que simples instrumentos manipulados por hombres pensantes.

Hay dos conclusiones a saber de Marcase, que las toma directamente de Carlos Marx:

La sociedad burguesa se ha ido gestando a medida que se vaciaba al obrero de todas sus determinaciones: primero sus labores directas, luego sin instrumentos propios y sin destrezas y habilidades específicas, finalmente como apéndice de la máquina que absorbe el proceso y deja al obrero como objeto disponible, arrebatándole su esencia que es eminentemente creativa.

La tecnología moderna que no solo tecnología física de las máquinas, sino que abarca también la tecnología de la administración de las personas y de los Estados tiende a borrar al hombre como ser genérico y lo hace esclavo de un progreso y un desarrollo no humano.

No pareciera, pero la tecnología es conservadora, y tiene su lado brusco. La forma reduccionista de cómo se hace ciencia es la responsable. Hablamos del paradigma imperante, del gran paradigma de Occidente, del modelo de Descartes, del modelo cartesiano:

C Sujeto - objeto

Alma - cuerpo

Espíritu - materia

Cualidad - cantidad

Finalidad - causalidad

Sentimiento - razón

Libertad - determinismo

- Existencia - esencia

Una salida certera es abandonar, es proponer una agrosocioeconomía distinta que arrastre todo lo demás, toda una concepción de vida integral. Nos referimos a una ciencia económica y social que busca impactos amplios en la mejoría de la calidad de vida, por lo 
cual debe rebasar el reduccionismo económico. En este sentido estudia los equilibrios entre: la forma y el contenido, lo formal y lo informal, lo superficial y lo sustantivo, lo instrumental y lo humano, lo cuantitativo y lo cualitativo, lo general y lo particular, la producción y la circulación. Esta economía del desarrollo debe reducir las brechas entre riqueza y pobreza, entre inclusión y exclusión.

Se tiene que alcanzar una visión no economicista, sino multidimensionsal de ampliación de las capacidades productivas a ampliación de las capacidades y opciones de las personas (consultar teorías de Amartya Sen). Esto, en términos del tema que compete significa que los pequeños productores pueden hacer tecnología. También, significa replantearse la propuesta de desarrollo, reconocer que no sólo pesan los rezagos estructurales como decía Rostow, sino el resultado de políticas nacionales e internacionales deliberadas, que terminan en una dinámica desigual de términos de intercambio como decía Prebish y que ahora se renueva en los replanteamientos de comercio justo de Joseph Stiglitz.

\section{3.- DEPENDENCIA TECNOLÓGICA: BASES DE LA DINÁMICA DEL CRECIMIENTO ECONÓMICO}

\section{1.- La Tecnología y los Estadios del Desarrollo}

Es Rostow (un clásico en teoría del desarrollo) quien nos convenció de la necesidad de establecer un carácter imitativo y gradual para llegar al desarrollo, es decir, los países sub desarrollados debían copiarse de los desarrollados, por lo demás apenas se trataba de que el tiempo transcurriera para llegar a tales fines. El desarrollo se asemejó a la dinámica natural de la creación donde los individuos nacen, crecen, se reproducen y mueren (con la salvedad de que el desarrollo no moriría - se transformaría cada vez en niveles superiores). El planteamiento se resume en cuatro etapas:

- Sociedad tradicional: La primera establece la base económica, el marco institucional y el sistema de valores.

- Previo al despegue: Se orienta hacia la productividad, actividades mercantiles, y la acumulación. 
- El despegue: Es la propiamente dicha, la etapa fuerte de inversión, cambio tecnológico, y de fortalecimiento de un sistema financiero.

- Camino a la madurez: Es la consolidación de logros de la sociedad industrial. Todo ello viene por un determinismo de una concepción lineal de ahorro e inversión.

Ciertamente el subdesarrollo afecta a todos los órdenes de la vida social y no sólo el económico. De aquí habrán dos consideraciones: la primera al estilo de Malthus que declaró la perennidad de la condición de pobreza y culpó a los pobres mismos por esa condición (según se decía: los pobres son holgazanes, ineficientes e irresponsables); la otra consideración la extraigo de José Antonio Alonso (Universidad Complutense, Economista Español), donde el subdesarrollo es un estado especial de vulnerabilidad; siguiendo las pautas que nos diera Rostow, sucede que no se han alcanzado ciertos estadios del desarrollo, y los culpables serían unos gobiernos débiles que dificultan sentar unas bases económicas, sociales e institucionales del desarrollo.

Esta teoría en términos básicos nos invita a seguir un modelo único del desarrollo, el de las tecnologías de punta, el modelo de la modernidad, de las ciudades y la agricultura competitiva de alta tecnología; se ratifica la división de roles donde a los subdesarrollados les corresponde la dotación de materias primas. Por otra parte, fija un simplismo de que alcanzar un nivel de desarrollo es cuestión de tiempo, que todos llegarán; con esto no se da esperanzas, sino invita a que cuando no funcione (que es casi siempre) no desmayar. Lo peor a lo que se afrontan los países, es la condición de dependencia de tecnologías y técnicas foráneas: La creatividad queda por demás y la asignación tecnológica la realiza el mercado, pues se nos escapaba decir que el Estado está llamado a no interferir en las esferas productivas.

Uno de los planteamientos resolutivos en este sentido, es un proceso de convergencia de la condición de desarrollo a la condición de subdesarrollo. En este asunto hay un nivel internacional y retos para la Cooperación al Desarrollo; también en los niveles nacionales la 
única forma de avanzar sería priorizando desde los niveles más bajos de productores y aplicación tecnológica.

A continuación se presenta un recorrido por las mal llamadas "teorías del desarrollo", prevaleciendo la simple presunción de que con ellas hay una aproximación a las tecnologías y eso lo define todo. Para estas teorías, lo más importante parece ser la fuerza de las tecnologías que son las determinantes del desarrollo y lo demás es contingencia, hasta la gente:

\section{2.- Adam Smith: Atención Contingencial de la Pobreza}

$\mathrm{Su}$ planteamiento del progreso es mediante la división del trabajo, incremento de la productividad y, vinculado al tamaño del mercado se libera el codiciado proceso de acumulación del capital. Los factores de producción, tierra, trabajo y capital, se combinan de forma óptima y se explotan al máximo. Se cae en el simplismo de que la sumatoria de los esfuerzos privados generará el bien común.

De Smith se puede derivar una preocupación por el pobre, pero solo se llegará a ellos por contingencia o por efecto derrame. Los productores pobres no están considerados en su lógica.

\section{3.- Thomas Robert Malthus: Un Desprecio Irracional por los Pobres}

Nos dice que el mundo perfecto de Smith por medio del crecimiento económico logrado, generará una demanda expansiva de bienes y mano de obra, se incrementarán los salarios, de paso la natalidad y ya los bienes no serán suficientes para alimentar a tan basta población.

Para Malthus, los pobres no dejarán de ser pobres por estar imbuidos en su círculo vicioso de pobreza. Hace una fuerte caracterización del pobre como el holgazán, vicioso y desobligado. 
3.4.- David Ricardo: Encasillamiento de la Pequeña Producción en Agricultura de Subsistencia

Si con el incremento de la población se requieren más alimentos, entonces se deben ampliar las tierras cultivadas, ir incluso hacia las tierras menos fértiles. También se puede salir del estancamiento a través del incremento de la productividad debido a la aplicación de mejoras tecnológicas y el aprovechamiento de las ventajas comparativas y competitivas del comercio internacional.

Desde Ricardo se le delega un poderoso papel a la tecnología en los niveles de productividad, se hace un llamado al crecimiento sin límites y a imponerse sobre la naturaleza (se hace una expansión de las fronteras agrícolas). Las nociones de desarrollo sostenible en estos momentos de Ricardo están en su mínima expresión...

Ahora bien, en la búsqueda de mejores tierras (o sólo tierras) se va desplazando a los campesinos hacia las peores tierras y hacia sitios inhóspitos, carentes de infraestructura productiva. De tal forma que los pequeños productores jamás alcanzarán las ventajas competitivas y están destinados a desarrollar prácticas de subsistencia (es este modelo el que explica en gran parte la condición de la pequeña producción y no casuales naturales).

Se destaca en Ricardo la denuncia antes que Marx, de la acumulación de un sector improductivo: el rentista y el señor comerciante.

\section{5.- Joseph Schumpeter: La Innovación Tecnológica desde una Clase} Empresarial Excluyente

$\mathrm{Su}$ aporte se concentra en el ámbito de la empresa y la microeconomía resaltando tres factores: movilización de factores y combinación; extensión del crédito; la presencia del empresario. La tecnología sigue jugando su rol preponderante y profundiza en las prácticas de innovación tecnológica que las define como la combinación de factores bajo nuevos usos. Para Schumpeter no es tanto la acumulación como la innovación. 
¿Quiénes son los sujetos Schumpeterianos? el empresario y el obrero individualista. De ahí en adelante, a la ciencia económica y a la política económica le ha sido difícil reconocer a otros sujetos económicos. En lo que al Estado respecta, debe hacerse a un lado y elaborar reglas claras de su intervención que en primer lugar favorezcan a la clase empresarial.

\section{6.- John Maynard Keynes: Propuesta de un Estado Débil, no Interventor, pero que es Garante de Resolver los Problemas a la Clase Empresarial Dominante}

El progreso económico desde la mirada de Keynes giró bastante. Entre otras cosas, introdujo la desconfianza en la capacidad autónoma del mercado y la conveniencia de un activismo estatal. La teoría keynesiana contribuyó a resolver la gran depresión de los años 30.

Los seguidores abusaron de los preceptos keynesianos, por lo que surgieron Estados despilfarradores o Estados populistas que igual terminaron en crisis productivas e inflacionarias. Esto dio la pauta para caer en el neoliberalismo férreo, aproximarse a las tecnologías de punta, la competitividad, la productividad, las exportaciones, la voracidad con la naturaleza, y excluir todo lo demás; y entre mayor contenido social más prohibitivo.

Cuando los privados están en crisis el Estado auxilia y cuando se trata de los pequeños productores o de los pobres no pasa nada, o bien la estrategia es de compensación social, dado que no son vistos como agentes económicos.

\section{7.- Opinión Concluyente: Un desarrollo para la Pobreza, lo Social y lo Cultural}

En este apretado recorrido es obvio que las teorías del crecimiento y los modelos cuantitativos son los que tienen validez internacional; en cambio las teorías del desarrollo, las que apuntan a corregir las deficiencias estructurales y proponer cambios sociales, se estudian, pero su aplicación es desarraigada (desafortunada). Urge comprender que la teoría general de los países en desarrollo no aplica, tampoco sus tecnologías. El desarrollo es 
normativo e incorpora la pobreza, lo social, la cultura; todas ellas variables insignificantes para la economía instrumental.

\section{4.- REDUCCIONISMO TECNOLÓGICO Y FACTORES PARALIZANTES DEL DESARROLLO INCLUYENTE}

\section{1.- Núcleos Capitalistas de Expansión Productiva que por Sobreacumulación Aportan Tecnologías Paralizantes}

La discusión práctica más próxima que uno puede sentir es la que reconoce no dos paradigmas distantes sino la realidad de dos tipos de economías: lo tradicional y lo moderno; aquello primero es de subsistencia y por lo segundo plantean los motores de la economía, de modo que los mecanismos excluyen la posibilidad de transformar a partir de la pequeña producción dejando todo el espacio transformador y propositivo a la gran producción:

Algunos autores, preconizan en una posibilidad de sobreacumulación, que refuerza la idea de sobreponer al sector moderno sobre el sector menos desarrollado. Para ellos la respuesta sencilla es encontrar el núcleo capitalista (es la vía de la riqueza de las naciones de Adam Smith que ahora masifica panfletariamente Alvin Toffler en La Revolución de la Riqueza). En realidad, la verdadera respuesta es encontrar al núcleo dispuesto a considerar sus acciones como parte de un esfuerzo superior; para tal fin el individualismo económico, las teorías de la especialización y demás, son de poca aplicación. La economía se desarrolla entre dos ámbitos: el moderno y el tradicional. El moderno dispone de fácil sobreacumulación pero no tiene vías ni propias ni alternas de distribución; y el sector tradicional está enraizado en la práctica de subsistencia, pero más que todo desorganizado. He aquí la paralización... 


\section{$\underline{\text { Riesgo de Sobreacumulación }}$}

a.- Se hace con trabajo, pero el sector tradicional no debe disponerse a ser la fuerza obrera, pues, siempre hay caminos para que sean parte de los motores del desarrollo.

b.- De los núcleos capitalistas de expansión, podríamos suponer a teorías de los conglomerados donde todos se enlazan y al final no pasa nada, sólo que el mercado local queda perfectamente ligado a las cadenas internacionales. Aunque la cohesión social se fraccione, para los apologistas del mercado todo estaría resuelto: el mercado queda intacto.

c.- La sobreacumulación da como consecuencia un reforzamiento de la trampa de la pobreza y la exclusión. Lo que podrían proponerse son grupos agregados de productores (cooperativos) que generen su producto acumulado: que de ahí a generar respuestas tecnológicas dista mucho y es lógico, pues las necesidades primeras de sustento y otras deben atenderse en ese nivel primario de prioridades. El mayor desconsuelo de cifrar esperanzas en la sobreacumulación sería pensar que los privados individuales pueden ceder su excedente de producción. Las entidades privadas grupales estarían más dispuestas, en una especie de fusión económica mixta con entidades de gobierno y desarrollo. Por un lado los privados grupales reciben facilidades, incentivos, hacen una producción que los lleva a un nivel superior (gozan de mayor excedente), ven claro su logro económico y haría falta generar la conciencia de disponer los excedentes a precios justos, de promoción de economías locales o bien canalizar sus productos a segmentos de mercado que el mismo mercado los ha dejado relegados.

Los países en desarrollo no pueden ahorrar e invertir porque son pobres y son pobres porque no pueden ahorrar e invertir; es un simplismo cierto, dado que no hay capacidad de ahorro. No obstante no puede ser ese el parámetro del desarrollo. El mercado no es espontáneo para pedir primacía y libertad absoluta. 
4.2.- Encadenamiento de Desequilibrios Tecnológicos y No Empujón o Arrastre Productivo

Gunnar Myrdal ya reconocía los efectos paralizantes de regiones donde hay que hacer correctores - estímulos y apoyo a la inversión si se quiere mantener la ventaja inicial. Para la dinámica paralizante es importante el activismo político, debe haber un encadenamiento de desequilibrios en virtud de empujón o arrastre. La política tecnológica está llamada a orientar los procesos de cambio...

Quedan algunos aprendizajes del núcleo capitalista:

- Hagamos una cadena para halar, engarzar los eslabones lo más cercano y lograr mayor beneficio. Esto va más de la mano con criterios de fuerza común o solidaridad, o cooperación. Todo indica que en el núcleo capitalista los del núcleo desaprovechan el potencial de los demás.

- El concepto de desarrollo ha venido mutando, ampliándose, pero en la práctica el mercado tiene poderosos mecanismos de asignación aparejados a poderosos mecanismos de exclusión...

\section{Comentarios sobre Factores Paralizantes}

Los núcleos capitalistas de expansión han tenido parálisis, han terminado en efectos paralizante y no era tan cierto que tienen asegurado el desarrollo; un efecto colateral es su poca capacidad de arrastre de otros sectores productivos.

Los gastos corrientes y también la inversión no siempre están disponibles en su magnitud, y los privados siempre hacen petición de capitales públicos y exenciones importantes de impuestos o prebendas fiscales.

- Hay factores que no deben descuidarse, sino promocionan la paralización: el capital humano, el marco institucional, lo educativo, las externalidades y las interdependencias. 
- No pocas veces mal se presupone que la guía es la economía externa y esta hace una asignación eficiente en el mercado.

- Para converger las diferencias entre el beneficio público y privado se requiere la intervención pública.

Una articulación insumo producto o la teoría del gran empujón son las cadenas...

Una mejor conclusión sobre los núcleos, las cadenas y agregaciones tecnológicas debe ser en adición a lo público. Esto no es nada parecido a estatizar las tecnologías, sino a crear un mecanismo alterno al mercado: el Estado con su voluntad política, los privados con su disposición de multiplicar, aplicar, crear, adoptar, los pequeños con su conocimiento local y con el reforzamiento técnico del Estado.

\section{3.- Tecnologías de Adición de los Bienes Públicos}

Para el desarraigo de las teorías del instrumentalismo económico podría ser más fácil admitir que las tecnologías son un bien público, más todavía que considerar que las tecnologías llegasen a plagarse de socioeconomía agropecuaria.

Asumiendo que la tecnología es un bien público se puede razonar que los beneficios son en función de todos y el usufructo es más elevado. Pero si tuviésemos limitantes de recursos, ya la tecnología no puede estar en función de todos. Y cuando se ha llevado a decisión la limitación de recursos versus la disposición de tecnologías, los menos han sido favorecidos (el supuesto llamado sector de ventajas competitivas), y los más (la pequeña y mediana producción) no han sido considerados.

De esto, en las economías en desarrollo han pasado dos observables: No se hacen mayores esfuerzos de transferencia (masificación tecnológica) y las transferencias cada vez más fueron enfocadas a la gran producción. 
José Antonio Alonso, economista español de la Universidad Complutense de Madrid propone mecanismos privados semipatentados de generación e innovación de tecnologías (o al menos mecanismos reconocidos que generen cierto premio al esfuerzo).

Lo planteado es revolucionario en el sentido de que la tecnología se genera en manos de los privados, y con esta base -entidades determinadas- hacen rastreo o rescate de tecnologías; se ofrecen los respectivos incentivos para que siga aflorando la innovación, y el bien tecnológico o proceso adquirido es difundido en otros grupos con características similares. Con lo que no se cuenta es que es difícil avanzar en la provisión de bienes cuando los niveles de pobreza y riqueza son tan desiguales. Lo otro difícil es cómo definir apropiadamente y diferenciar entre las aportaciones individuales y los niveles agregados de provisión de bienes.

¿Cómo opera el proceso de tecnologías de adición de los bienes públicos?

Al mecanismo se le denomina “Bienes de Suma Simple”. La suma simple hace la provisión agregada del bien público, y puede ser en dos niveles:

Nivel Superior.- El nivel agregado es determinado por aquel que realiza la máxima aportación.

Nivel Inferior.- Son bienes de suma ponderada. El supuesto es que todos están dispuestos del más al menos a ceder su nivel máximo de aportación.

En suma simple y nivel inferior la contribución de los países en desarrollo puede ser crucial... con un determinante esfuerzo de todos. Pasa por mejorar la posición de los más (la pequeña producción) e involucrarlos en la generación de tecnologías; también hay que enmendar las capacidades institucionales y técnicas; y los centros de investigación deben aproximar sus técnicas a las voluntades y decisiones de políticas. 


\section{Principios de Intervención en la}

\section{Adición de Bienes Públicos}

a. En lo que respecta a la Cooperación.-

1. Lo primero es lo propio de la acción: inversión en conocimiento e investigación básica para desarrollo de tecnologías de dominio público.

2. Lo segundo, generar los mecanismos para revertir potenciales efectos adversos, inversiones en infraestructura, gestión de recursos naturales, entre otros. Algo que no debe quedar fuera de la forma de hacer, es que la generación de tecnologías es un asunto de grupos.

3. Lo tercero, no están por demás algunas acciones individuales de generación de tecnologías, aunque el usufructo siempre puede ser común. Los mercados de tecnologías tendrían que variar su orientación comercial.

b. Hay actividades centrales y otras complementarias, primero es producir el bien público, y la otra es prepararse para el consumo, para los procesos de adopción de tecnologías.

c. Los pequeños productores pueden delegarse actividades complementarias a fin de contribuir en el proceso de generación de tecnologías para ser más fácilmente absorbidas por ellos mismos.

d. En este ámbito de generación de tecnologías privadas, locales, de pequeña producción y con una reconversión a bien público a través de la intervención de las entidades públicas, sucede que “lo local no es lo local”; significa que una vez validada la tecnología, debe trascender y masificarse su adopción a nivel de país y hasta región, de modo que nadie en particular se apropia o patentiza el resultado. 
e. El principio rector no sólo es financiación y provisión, sino también producción de tecnologías y efectivo consumo de bienes.

f. Sobre la reducción de la pobreza: La adición de bienes públicos es un mecanismo de reducción de pobreza: La superación de la pobreza extrema presenta, al menos de forma parcial, los rasgos propios de un bien público impuro: un bien de reproducción conjunta. De la misma forma, la solución de la pobreza rural puede pasar por la dotación de un bien público ${ }^{9}$ llamado tecnología y que tiene que difundirse a niveles masivos.

g.- Las externalidades del mercado de tecnologías expresadas en daños ambientales tienen que ser internalizadas por quien provoca el daño o en su defecto, el Estado debe reponer los daños sociales incurridos.

h.- El mercado tiene su falla fundacional siendo que restringe el nivel de uso de las tecnologías porque la única forma de llegada a las mismas es a través de recursos financieros. Otros de los intereses del mercado es lo estrictamente técnico, lo tecnocrático. Esto es parte de lo que se denomina la "primera tradición”.

i.- Es necesario reconocer el valor delimitador y de empuje de cambios de los procesos de decisión social. A esto se le denomina la "segunda tradición" que otorga a la tradición del bien público un trazado cambiante en el tiempo, acorde con los resultados que impone la dinámica social y el cambio histórico. Según algunos autores, en este entorno el concepto de tecnología e innovación pierde precisión, abstracción y límites indiscutibles, pero gana en capacidad interpretativa.

j.- Hay que estar atentos en los procesos de generación de tecnologías, de eliminar comportamientos oportunistas “free rider". Significa que algunos actores se escudarán de

\footnotetext{
${ }^{9}$ Un bien público genera beneficios para todos de una forma no limitada. Se trata de bienes que no son excluyentes, bienes de beneficios no rivales, su consumo de un agente no limita la capacidad de disfrute de otro, y casi siempre es ofrecido por el Estado.
} 
las responsabilidades y de los aportes monetarios y no monetarios, pero buscarán gozar de los productos finales.

\section{5.- TECNOLOGÍA PARA EL DESARROLLO ${ }^{10}$}

En Denis Goulet -en su guía teórico y práctica sobre la ética del desarrollo- se refrendan algunas dicotomías importantes que es necesario tenerlas en cuenta al momento de aplicar política tecnológica a efectos de no caer en la sinrazón de la instrumentalización. Goulet define La Racionalidad de la siguiente forma:

\section{1.- Racionalidad}

"Ser racional es contemplar una serie de procesos, no es la verdad, sino la verificación, la observación y la prueba cuantitativa de que algo es lo que parece ser".

En consecuencia se critica lo verificable de muchos procesos tecnológicos que finalmente reportan logros, pero muy pocos están directamente vinculados con el quehacer humano, con su mejoría y trascendencia del productor, de él, los suyos y su generación.

Es muy cierto que la tecnología genera libertades. Así, lo profiere Goullett: "Las represas, los insecticidas y los sistemas de riego hacen que las comunidades agrarias sean menos vulnerables que antes a los caprichos de la naturaleza como a las inundaciones, sequías y plagas de insectos". Pero también las tecnologías crean limitaciones de dependencia, y esta es la parte menos profundizada. Dichas limitaciones repercuten en mayor o menor grado en los sistemas agrarios, su organización social, su dinámica productiva, el ambiente de las relaciones sociales de producción, como el ambiente natural. Y lo más dañino sería el acostumbramiento a adoptar solamente lo que vierte el mercado y más aún, a no reconocer

\footnotetext{
${ }^{10}$ Para este apartado, quien mejor ilustra el conocimiento es Denis Goulett, Ética del Desarrollo: Guía Teórica y Práctica sobre la Ética del Desarrollo. En Goullett, también descansa todo el fundamento filosófico y el trasfondo, por demostrar que es posible una generación de tecnologías para el desarrollo...
} 
el potencial innovador del conocimiento local, una historia productiva que es cultura, forma de vida y razón de ser de las comunidades. Entonces, si queremos racionalidad tecnológica debe iniciar por un llamado a la TECNOLOGÍA ENDÓGENA, un restaurar del movimiento innovador, campesino, artesanal y propio de las identidades y necesidades de cada comunidad agrícola. Y la comunidad es el cooperativismo, el asociativismo, el juntarse para llegar a otro nivel de capitalización: la simple relación costo beneficio no sabe de estos parámetros.

No se trata de una apología al conocimiento local, ni mucho menos un desprecio a la ciencia, a la técnica, a lo que se ha hecho y sigue en marcha mediante las revoluciones tecnológicas. Ya desde Marx se planteaba la dicotomía entre el artesano y la máquina (¿quién hará los productos?); al ser la máquina la preponderante deviene una expulsión de obreros: la llamada fuerza de reserva laboral que no es más que un ejército de desempleados. Así se configura uno de los mayores roces de la tecnología. Según la historia industrial de Inglaterra ya han existido guerras técnicas:

a) En 1811 se dieron actos de violencia contra las máquinas.

b) En 1812 hubo tiroteos por la misma razón.

c) En 1813 en la ciudad textil de Nottingham se reportaron grandes movimientos de protesta contra la deshumanización de la vida, provocada por los instrumentos de la tecnología.

En el debate reciente, el economista Frank Hinkelammert del Departamento Ecuménico de Investigación de Costa Rica, se refiere a la expulsión laboral como "estancamiento dinámico" donde las economías crecen a la par del crecimiento en los índices de desempleo. Para Hinkelammert este es el colmo de una economía liberal. Por su parte el economista Win Dierkszen del Fondo Mundial de Alternativas, plantea algo así como la trampa de la tecnología, en el sentido que desde la tecnología se arrecian los niveles de competencia y estos, cada vez son más evidentes entre grandes corporaciones y/o conglomerados. Los ajustes a las nuevas tecnologías cada vez son más rápidos y se achican los espacios entre los competidores, todo ello a un altísimo costo monetario. Siendo así, la 
racionalidad tecnológica está altamente comprometida y cada vez más entra en un surco sin salida.

En esa llamada racionalidad hay algo que siempre está obviado.- las tecnologías no son neutrales:

La tecnología nunca actúa en el vacio: Está creada y se emplea dentro de un contexto social concreto y para conseguir determinados fines, como obtener ventajas en la guerra, en la negociación política (utilizando la amenaza de la guerra) y en el comercio. Hay además grupos concretos que tienen un enorme interés en promover ciertas formas de tecnología (Denis Goulet).

No es remoto pensar que según los grupos en el poder, las tecnologías caminan por ahí...

\section{2.- Eficiencia}

Lo que más pide el criterio de racionalidad es la eficiencia, la cual de ser un parámetro para que el conjunto de criterios o insumos resulten en un producto integral, se convierte en el afán de la productividad. Michael Porter es uno de los mayores defensores, de acuerdo a su planteamiento "la productividad es la principal determinante del nivel de vida de una nación”. Y se insiste en el argumento por más que se compruebe que la productividad en casi todos los casos es indiferente a mejorías en niveles de vida y de pobreza. No obstante, para los mentores como Porter resulta difícil desprenderse de las teorías simplistas y economicistas del derrame: En este caso, a la mercadotecnia la visten de desarrollo.

\section{3.- Creación-Destrucción de Cultura y Valores}

Teniendo la claridad de que la tecnología no es neutral, donde más repercute y donde menos se analiza es en la cultura y valores de las comunidades rurales, sobretodo de países sub-desarrollados o en proceso de desarrollo. Así, con el médium de la tecnología podemos incrementar la productividad, pero también crear o destruir cultura y valores. Si queremos hacer mejoras sustantivas, la evidencia indica que tenemos que tomar distancias de las 
tecnologías de punta, de aquellas nociones únicas y miméticas del desarrollo, tenemos que darnos a innovar frente a la histórica dependencia tecnológica; esto de nuevo es la propuesta de la TECNOLOGÍA ENDÓGENA. ¿Podríamos hacer la pregunta ingenua de si la tecnología sirve? Y sabemos que sí y la promulgamos, con un poco tomado de afuera y otro más creado en las comunidades, con la guía de científicos agrosocioeconomistas que se transfiguran en simples instrumentos de cambio.

El mensaje de Goulet al respecto es el siguiente:

La verdad es que el optimismo tecnológico -la creencia de que la tecnología puede destruir la miseria en una generación- puede ser peligroso.

Implícitamente se reconoce que la tecnología también puede atender el tema de la pobreza, pero es necesario responder varias preguntas: ¿qué tipo de tecnología? no las de punta; ¿con qué sujetos? no los más dinámicos, ellos no son los necesitados, pues adoptar tecnologías no es su mayor cuello de botella; ¿qué técnicos? no los cientistas puros que se aferran a la validación experimental y al laboratorio; ¿qué nutre al conocimiento? no la verborragia de la historia de las revoluciones tecnológicas, sino el conocimiento local que está impreso en el sentir de la gente del campo; ¿qué cultivar? una guía es el mercado y la otra también fuerte son aquellos cultivos que ya son en sí mismos formas de vida, de conductas y relacionamientos socio-productivos. Ahí, en esas respuestas está el germen de la tecnología: una sin patentes, y por lo contrario, con la disposición de multiplicarse y dotarla para todos.

\section{4.- El Poder del Conocimiento Local es más que Tecnología}

Haremos contraste del "mundo local" y del "mundo occidental": lo local lo designaremos como el mundo agrario rural y de comunidades pobres. El mundo occidental es una concepción imperante de desarrollo único y dependiente. Las diferencias se concentran en los distantes entendimientos de la eficacia y los valores implicados: 


\begin{tabular}{|c|c|c|}
\hline Categorías & $\begin{array}{c}\text { Lo local: } \\
\text { nuestra ruralidad }\end{array}$ & El mundo occidental \\
\hline Eficacia & $\begin{array}{lr}\text { La eficacia es más que } & \text { que } \\
\text { trabajo manual, es más que } \\
\text { productividad. La eficacia } \\
\text { y productividad } & \text { son } \\
\text { términos que expresan una } \\
\text { relación de vida y } \\
\text { cuantitativa. } \\
\text { interiorizan valores como } \\
\text { el deber } \\
\text { obligaciones de parentesco, } \\
\text { talento artistico, entre } \\
\text { otros. }\end{array}$ & $\begin{array}{l}\text { La noción occidental } \\
\text { exterioriza esos valores del } \\
\text { concepto de eficacia, a veces } \\
\text { a costa de la destrucción } \\
\text { cultural. }\end{array}$ \\
\hline Valores & $\begin{array}{l}\text { Muchas } \\
\text { culturales de los países en } \\
\text { desarrollo han vivido en un } \\
\text { mundo mítico y continúan } \\
\text { viviendo el mito como no } \\
\text { menos real que la historia. } \\
\text { En cambio occidente adolece } \\
\text { de la necesidad del mito y } \\
\text { la simbología. }\end{array}$ & $\begin{array}{l}\text { En occidente son susceptibles } \\
\text { de la manipulación ideológica } \\
\text { y simbólica porque obran en } \\
\text { un vacío del mito. }\end{array}$ \\
\hline $\begin{array}{l}\text { Solución de } \\
\text { problemas } \\
\text { tecnológicos }\end{array}$ & $\begin{array}{ll}\text { Rechazan experimentos y } & \text { y } \\
\text { tratan de } & \end{array}$ & $\begin{array}{lrr}\text { Se basan en los impactos } \\
\text { previsibles la } \\
\text { transferencia de tecnologías. } \\
\text { Los tecnócratas } \\
\text { posiciones distantes, no hay } \\
\text { nada sagrado, ni la tierra, } \\
\text { ni la naturaleza. }\end{array}$ \\
\hline
\end{tabular}

\section{5.- Las Falacias de las Tecnologías de Punta}

a.- Un solo paquete tecnológico es la receta: Los procesos van orientados hacia la estandarización y hacia los paquetes tecnológicos: la gran escala, mucho capital y poca mano de obra. Mediante este proceso se descuidan las necesidades agrosocioeconómicas y locales; todo es una contrariedad al desarrollo cuando no se tiene en cuenta la problemática de las latitudes de países subdesarrollados: en ellos no hay escalas mayores, se padece desempleo, hay déficit de formación y faltan recursos financieros, de modo que hacer o adoptar tecnologías es en muchas dimensiones más costoso. Ahí -en medio de esos problemas- la pequeña escala tendría que ser más eficiente. 
b.- El mercado asigna toda la rudimentaria tecnológica: Supone la existencia de poder adquisitivo en un gran número de productores / compradores. La verdad es que el poder de compra de tecnologías en los países en desarrollo es mínimo, porque los productores apenas están lidiando con la posibilidad de obtener los insumos básicos de producción. Cuando hablamos de desarrollo de mercados de tecnología, creo que este es el punto donde no se ha llegado.

c.- La cientificidad ante todo: Ocurre que la cientificidad se opaca en la soga de su abstracción. Cuando los extensionista e investigadores, actúan sesgados en su especialización, entonces se vuelven insensibles a los prejuicios sociales, y su intervención termina en perjuicio a la cultura.

d.- La tecnología de punta es la solución: Es la falacia más fácil de desestimar, puesto que para adoptar tecnologías de punta se requiere de unas condiciones que no son propias de la actividad agropecuaria de la pequeña y mediana producción, hasta a veces de la gran producción. Como decíamos antes, la capacidad de reemplazo de tecnologías de punta es a través de un alto costo de oportunidad, que puede terminar en pérdida económica.

La respuesta frente a las tecnologías de punta son las tecnologías apropiadas, donde empieza a haber cierto acuerdo. No obstante hay varias modalidades derivadas, entre las cuales hay que seleccionar:

- Para unos basta con elegir la tecnología adecuada. Es única, está de la mano con noción de paquete tecnológico, y se refiere a elementos tangibles.

- Para otros no debería elegirse una tecnología adecuada, sino más bien hacer una selección adecuada de una serie amplia de tecnologías. Sigue siendo tangible, concreción instrumental.

- Otra modalidad más avanzada es la que va hacia los impactos y quizá por ahí es donde debe venir la comprensión de las TECNOLOGÍAS PARA EL DESARROLLO: 
Diría Goulet: ...hay que estar atentos a las prioridades del desarrollo, disponibilidad de recursos, a los posibles efectos de las distintas tecnologías sobre la distribución de la renta, al desempleo y a la conservación del medio ambiente y a la supervivencia cultural.

Lo importante detrás de las tecnologías adecuadas es que hay posibilidad de selección y se empieza a construir un mecanismo de asignación extra mercado. En lo que respecta a las tecnologías de punta, no son exactamente lo mejor; por ello, los tomadores de decisiones que impactan en grandes y pequeños grupos- tienen que pensar seriamente en lo que son las políticas de selección y aplicación de tecnologías apropiadas para las condiciones ambientales, culturales, políticas e históricas de una determinada población.

\section{6.- Propuesta de Acción de Tecnologías Adecuadas}

Las tecnologías y el desarrollo.

- La tecnología es fuente de desarrollo y la mejor forma de aprovecharla es domesticando el desarrollo. Es necesario ejecutar respuestas directas a las dificultades planteadas a lo largo del proceso de producción. La transferencia de tecnología debe conocer ya algo de los problemas: Debe ser parte del proceso de formulación del problema...

\section{La sostenibilidad mediante las tecnologías.}

Emplear de forma óptima los recursos internos.

Estar en armonía con el medio ambiente.

Reconocer la importancia de las deseconomías de escala, las hay culturales y psicológicas. En ello radica la eficacia de la pequeña producción.

\section{Sistema de incentivos incluyentes: Una política expresa}

Apuntar primero hacia la satisfacción de las necesidades básicas de la producción. 
Dictar con claridad la política de innovación tecnológica, aunque siempre es un marco referencial y una guía que no lo es todo.

- Incentivar a la pequeña producción a través de financiamiento en primer lugar y después de mecanismos alternativos y seguros de recibir beneficios tecnológicos.

\section{EI acceso}

Acceder a las tecnologías es la máxima, justa y revolucionaria contribución que se puede hacer a favor de los pequeños y medianos productores.

- Concienciar de que el prestigio, la eficacia y eficiencia de las tecnologías está más allá de la aceptación del mercado.

- Hacer de la generación de tecnologías locales un bien de acceso masivo.

- Intervenir los mercados de tecnologías excluyentes.

- Dinamizar los mercados de tecnologías a precios justos.

\section{Conocimiento Local}

No desestimar los lugares productivos más modestos, que son capaces de generar una masa crítica de innovación tecnológica. En este caso los consejos de ancianos o productores, o como queramos llamarles, pueden ser tan transformadores como un grupo de expertos.

- Practicar la asesoría a la reversa: los investigadores y extensionistas están ávidos de ser asesorados.

- Promover la autosuficiencia en la inventiva tecnológica (esto desde el productor hasta el país).

- Reducir la dependencia foránea de tecnologías.

- Considerar siempre los recursos locales y las medidas de política también deben ser ajustadas a una condición de desarrollo local.

A fin de reforzar las propuestas de acción, se dejan dos conclusiones que abonan porque la política de innovación y las innovaciones mismas tengan en cuenta a la pequeña producción: 
Primera.- La política tecnológica para el desarrollo funciona mejor en sociedades que quieren experimentar con escalas y modos diferentes de tecnologías. Aunque algunas tecnologías favorecen determinados constelaciones sociales de valores, otras refuerzan valores completamente diferentes.

Segunda.- En la política tecnológica como en la planificación del desarrollo, la mejor prudencia es buscar soluciones experimentales que respondan progresivamente a las lecciones extraídas de la experiencia. Por esta razón, si no es por otra, la política tecnológica debe favorecer muchas innovaciones pequeñas, más que pocas grandes (Goullet 215).

\section{6.- A MANERA DE CONCLUSIÓN: ESCENARIOS FUTUROS DE DESARROLLO TECNOLÓGICO}

Ahora bien, fijada una idea de cómo hacer tecnologías para el desarrollo (proceso o política de innovación tecnológica), no quiere decir que ya no hay posibilidades de proponer y rehacer; lo que hemos querido decir es apenas que no hay desarrollo tecnológico único. Hemos querido decir que por la vía ortodoxa de generación de tecnologías, que se ha propuesto (impuesto) no se ha llegado al desarrollo de los países pobres. A continuación, algunos escenarios posibles del desarrollo tecnológico:

1.- Política de Crecimiento: El escenario menos apropiado es el del crecimiento económico. Aquí hay una insistencia en la dinámica, el marco normativo, las etapas de Rostow, la convergencia o cierre de brechas cuantitativas, crecimiento de la producción nacional, renta per cápita, entre otros.

2.- Política de Desarrollo: Con relación a la política de desarrollo hay varios caminos a saber:

- El mundo es desigual pero camina hacia una convergencia.

- Un escenario es la política de desarrollo como política de crecimiento.

- Una política generalizada del desarrollo. 
3.- Escenario de Trasnacionales o Tecnologías Foráneas ${ }^{11}$ : Es necesario revisar lo que todavía puede esperarse de las multinacionales. Hasta ahora el impacto en términos de generación de empleo y transferencia tecnológica no ha sido efectivo: hay crecimiento con desempleo y las tecnologías no están dispuestas para las condiciones socioeconómicas de los pequeños productores. De no reenfocarse esta estrategia, entonces se puede transfigurar en el escenario de dependencia tecnológica eterna, donde las filiales de las empresas transnacionales no brindan ningún estímulo para actividades tecnológicas locales.

4.- La Innovación Endógena: Fue la respuesta y la experiencia del sudeste asiático. Nunca hubieran podido confrontarse con la competencia del mercado internacional si antes no hubiesen realizado sus propios avances tecnológicos (sus prácticas de desarrollo endógeno). Ellos hicieron verdadera sustitución tecnológica, eliminando todos los estímulos para adopción de tecnologías del norte, por lo contrario promovieron sus propias innovaciones.

5.- Contrariando la Gran Escala: Otro escenario que en este marco es posible: un mínimo de transferencia tecnológica para apoyarse en la producción intensiva de mano de obra. Si no un escenario puro, siempre habrá espacios donde multiplicar esta práctica.

\section{6.- La Nueva Industrialización ${ }^{12}$ :}

Existe una ola de nuevos países industrializados y ciudades de alta tecnología, donde el campo no aparece como un escenario de reproducción de tecnologías, lo cual es un grave error que puede hacer revertir los avances alcanzados.

\section{7.- La Revolución Informática y otros:}

Es una especie de pasarela al uso del capital: los medios de comunicación, los programas de estudio, y otros. Tiene de trasfondo un afán ilusorio por las tecnologías de punta y la gran producción.

11 Tomado de "El Huracán de la Globalización", Frank Hinkelammert, Departamento Ecuménico de Investigación, páginas 152-153.

${ }^{12}$ Ampliar más en Maryse Brisson. La Globalización Capitalista: Una Exigencia de las Ganancias. La Nueva Propuesta Postmodernista. Páginas 96 a 99. 
8.- La Verdadera Revolución Tecnológica ${ }^{13}$ : Se necesita una revolución cultural en la socio - economía aparejada a la revolución del capitalismo, y que lo trascienda, lo humanice, y lo reenfoque en la gente.

\footnotetext{
${ }^{13}$ Para más detalles ver: Coordinación social del trabajo, mercado y reproducción de la vida humana: Preludio a una teoría crítica de la racionalidad reproductiva, pág. 189, Franz J. Hinkelammert - Henry M Mora, Colección Economía y Teología 2001.
} 


\section{BIBLIOGRAFÍA}

Amin, Samir y Francois, Houtart. Globalización de las Resistencias: El Estado de las Luchas 2005. Caritas Española. 1ra. Edición. Madrid, 2005.

Amin, Samir. Por un mundo multipolar (El Viejo Topo). Intervención Cultural. 1ª Edición. Mataro, 2006.

Amin, Samir. Por la Quinta Internacional (El Viejo Topo). Intervención Cultural. 1a. Eidición. Barcelona, 2007.

Amin, Samir. El Imperio del Caos: La Nueva Mundialización Capitalista. IEPALA Internacional. 1ra. Edición, Madrid, 2008.

Amin, Samir. El Socialismo en el Siglo XXI. Reconstruir la Perspectiva Socialista. IEPALA Editorial. 1ra. Edición, Madrid, 2009.

Amin, Samir. La Crisis del Capitalismo o Salir del Capitalismo en Crisis. (El Viejo Topo). Intervención Cultural. 1ra. Edición, Madrid, 2009.

Alonso, José Antonio. Abril de 2003. Material de Trabajo de Postgrado Latinoamericano de Trabajo Social (UNAH - PLATS). Doctorado en Ciencias Sociales con Orientación en Gestión del Desarrollo. Módulo I - Tomo VIII. Teoría Crítica del Desarrollo. Modelos de Desarrollo. Epistemología y Ética. Crecimiento y Desarrollo: Bases de la Dinámica Económica (Un recorrido por las Teorías del Desarrollo).

Chomsky, Noam. Reflexiones acerca del lenguaje. Adquisición de las estructuras cognoscitivas. Trillas. Primera reimpresión, mayo 1986, México.

Chomsky, Noam. Science and Ideology. Jawaharlal Nehru Memorial Lectures: 1967 - 1972 Nehru Memorial Fund, Nueva Delhi, Bombay: Bharatiya Vidya Bhavan, 1973 c.

Chomsky, Noam. American Power and the New Mandarins. Nueva York, Pantheon Books, 1971.

Daly, Herman E., y Cobb, John B. Para el bien común. Reorientando la economía hacia la comunidad, el ambiente y el futuro sostenible. Fondo de Cultura Económica. Bogota, Colombia, 1997.

Descartes, René. El Discurso del Método. AKAL. 1ra. Edición, Madrid, 2007.

Dierckxsens, Win. El Ocaso del Capitalismo y la Utopía Reencontrada: Una perspectiva desde América Latina. Departamento Ecuménico de Investigación (DEI). Foro Mundial de 
Alternativas (FMA). Ediciones desde abajo. Colección Universitaria. Tercera Edición Ampliada. Costa Rica, DEI, Colombia, Marzo de 2003.

Dierckxsens, Win. Los Límites de un Capitalismo sin Ciudadanía: Por una mundialización sin neoliberalismo. Departamento Ecuménico de Investigación. Colección Universitaria. Tercera Edición Ampliada. Costa Rica, DEI, 1997.

Duchrow, Ulrico, y Hinkelammert, Franz J. La Vida o el Capital: Alternativas a la dictadura global de la propiedad. Departamento Ecuménico de Investigación- Colección Economía - Teología. Costa Rica, DEI, 2003.

Fayol, Henry. Principios Generales de Administración. Tomado de Clásicos en Administración, páginas 185 - 206, Harwood F. Merril, LIMUSA, México - 1978.

Friedman, Milton. "Paro e Inflación”. Unión Editorial, S.A., Madrid, España. 1977.

Friedman, Milton y Rose. Libertad de Elegir. Hacia un nuevo liberalismo económico. Grijalbo, 1980. Impreso en España. Traducido por Carlos Rocha Pujol.

Goulett, Denis. Ética del Desarrollo: Guía Teórico y Práctica (Universidad de Notre Dame).

Hinkelammert, Franz J. El Asalto al Poder Mundial y la Violencia Sagrada del Imperio. Departamento Ecuménico de Investigación. Colección Economía - Teología. Costa Rica, DEI, 1999.

Hinkelammert, Franz J. (Compilador). El Huracán de la Globalización. Departamento Ecuménico de Investigación. Colección Economía - Teología. Costa Rica, DEI, 1999.

Hinkelammert, Franz J., y Mora, Henry M. Coordinación Social del Trabajo, Mercado y Reproducción de la Vida Humana: Preludio a una teoría crítica de la racionalidad reproductiva. Departamento Ecuménico de Investigación. Colección Economía - Teología. Costa Rica, DEI, 2001.

Hinkelammert, Franz J. Cultura de la Esperanza y Sociedad sin Exclusión. Departamento Ecuménico de Investigación. Colección Economía - Teología. Costa Rica, DEI, 1995.

Hinkelammert, Franz J.; Mora Jiménez, Henry. Hacia una Economía para la Vida. DEI: Departamento Ecuménico de Investigación. Colección Economía - Teología. 2005, San José, Costa Rica.

Hinkelammert, Franz J.; Crítica a la Razón Utópica. Tercera Edición. Colección Economía - Teología. Departamento Ecuménico de Investigación. 2000, Costa Rica.

Kalecki. Michael. Teoría de la Dinámica Económica. Fondo de Cultura Económica, México - 1956. Ensayo sobre los movimientos cíclicos y a largo plazo de la economía capitalista. 
Keynes, J.M. "Carta dirigida al Presidente Franklin D. Roosevelt". Publicada en New York Time, el 31 de diciembre de 1933.

Keynes, J.M. Teoría General de la Ocupación, el Interés y el Dinero. Fondo de Cultura Económica / Serie de Economía. México. 1997. 14 Reimpresión.

Kotler, Philip. Dirección de Mercadotecnia. Octava Edición. Análisis, Planeación, Implementación y Control. Prentice Hall. Impreso en México, 1996.

Kotler, Philip. Los 80 conceptos esenciales de marketing. De la A a la Z. Pearson, Prentice Hall. Última reimpresión 2006. Impreso en España.

Magariños, Mateo. Diálogos con Raúl Prebisch. Banco Nacional de Comercio Exterior. Fondo de Cultura Económica. Economía Latinoamericana. Impreso en México. Primera Edición, 1991.

Malthus, Thomas Robert. Primer Ensayo sobre la Población. Alianza Editorial - 15. Madrid 1993. Impreso en Printer Industria Gráfica, S.A., San Vincenc dels Horts, Barcelona, Madrid. Séptima Reimpresión, de la primera en "Libro de Bolsillo" en 1966.

Marcuse, Herbert. La racionalidad tecnológica y la lógica de la dominación. El hombre unidimensional, Beacon Press, 1964.

Marx, Carlos. Crítica de la Economía Política y Miseria de la Filosofía. Editora Nacional (304) - México 7, D.F., 1976. EDINAL Impresora. Versión Española de Javier Merino.

Marx, Carlos. El Capital. Tomo I, II y III. Editorial Librerías Allende, S.A. Crítica de la Economía Política. Editorial Cartago. Impreso en México.

Maquiavelo, Nicolás. El Príncipe. Edición Original: Florencia 1513. Edición Electrónica: 2004. www.laeditorialvirtual.com.ar

Morin, Edgar. El Método 1. Cátedra. 7ma. Edición. Madrid, 2006.

Myrdal, Gunnar. La pobreza de las naciones. Asian drama. An inquiry into the poverty of nations. Siglo XXI, 1975. Traducción por: Joaquim Sempere.

Popper, Karl. Alianza Editorial, S.A. Madrid, 1973. Impreso en Ediciones Castilla. La Miseria del Historicismo (The Poverty of Historicism).

Porter, Michael. Estrategia Competitiva. Técnicas para el Análisis de los Sectores Industriales y de la Competencia. CECSA. Edición Revisada. Trigésima Quinta reimpresión. Compañía Editorial Continental. México. 
Porter, Michael. Ventaja Competitiva. Creación y sostenimiento de un desempeño superior. Grupo editorial patria. Edición revisada. 6ta. Reimpresión. México 2009.

Prebish, Raúl. Nueva Política Comercial para el Desarrollo. Fondo de Cultura Económica / Economía Contemporánea. México, D.F. Sección Obras de Economía. Informe de Raúl Prebish a la Conferencia de las Naciones Unidas sobre Comercio y Desarrollo, inaugurada en Ginebra, Suiza, marzo de 1964.

Prebish, Raúl. Introducción a Keynes. Sección Obras de Economía. Fondo de Cultura Económica, México. Primera Edición, 1947. Segunda Reimpresión, 1977.

Ricardo, David. Principios de Economía Política y Tributación. Fondo de Cultura Económica, México, 1985.

Robinson, Joan y Estwell. Introducción a la Economía Moderna. Fondo de Cultura Económica, México.

Rostow, W.W., The Stages of Economic Growth, Cambridge University Press, 1971.

Schumpeter, Joseph. Teoría del Desenvolvimiento Económico. Fondo de Cultura Económica. Sección Obras de Economía. Impreso en México, de la obra original escrita en Cambridge, Massachusetts, Marzo de 1934.

Sen, Amartya y Kliksberg, Bernardo. Primero la Gente: Una mirada desde la ética del desarrollo a los principales problemas del mundo desarrollado. Ediciones DEUSTO. Barcelona, 2007.

Serrano, Augusto. La Aventura del Conocimiento. LOGOS, Ediciones Banco Central de Honduras. Tegucigalpa, 1995.

Serrano, Augusto. Desarrollo Humano Sostenible. Material Manuscrito (en versión borrador para publicación). Marzo 2003. Utilizado en el Módulo I - Tomo IV. Teoría Crítica de las Teorías del Desarrollo. Modelos de Desarrollo. Epistemología y Ética. Material del Postgrado Latinoamericano de Trabajo Social de la Universidad Nacional Autónoma de Honduras. Doctorado en Ciencias Sociales con Orientación en Gestión del Desarrollo.

Serrano, Augusto. Educación Superior para el Desarrollo Humano Sostenible. Una propuesta de investigación institucional en la UNAH. Noviembre de 2004. Universidad Nacional Autónoma de Honduras. Postgrado Latinoamericano en Trabajo Social. Doctorado en Ciencias Sociales con Orientación en Gestión del Desarrollo.

Serrano López, Augusto. Crítica de la Razón Científica. Material del Doctorado en Ciencias Sociales con Orientación en Gestión del Desarrollo. UNAH - PLATS. Módulo I, Tomo III. Tegucigalpa, Marzo de 2003. 
Smith, Adam. Investigación sobre la Naturaleza y Causas de la Riqueza de las Naciones. Economía. Fondo de Cultura Económica. Edición de Edwin Cannan con una introducción de Max Lerner. Nueva traducción y estudio preliminar de Gabriel Franco. 54.- Primera edición en inglés, 1776. Decimosexta reimpresión, 2008. Impresa en México desde 1958 por el Fondo de Cultura Económica.

Stiglitz, Joseph. El malestar de la globalización. Taurus - Pensamiento. Traducción de Carlos Rodríguez Braun. Impreso en México, 2002.

Stiglitz, Joseph. Cómo hacer que funcione la globalización. Taurus. Impreso en México, Noviembre de 2006. Traducción de Amado Diéguez y Paloma Gómez Crespo.

Stiglitz, Joseph. Caída Libre. El Libre Mercado y el Hundimiento de la Economía Mundial. Taurus. Primera edición, abril de 2010. Traducción de Alejandro Pradera y Núria Petit.

Stiglitz, Joseph y Charlton, Andrew. Comercio Justo para Todos. Taurus - Pensamiento. México, Julio de 2007. Traducción: Natalia Rodríguez Martín.

Tablada, Carlos, y Dierckxsens, Wim. Guerra Global, Resistencia Mundial y Alternativas. Editorial de Ciencias Sociales, La Habana, 2003.

Toffler, Alvin y Heidi. La revolución de la riqueza. Debate. Traducción de Julia de Jodar. Impreso en España, 2006.

Wolfensohn, Jame D. Propuesta de un marco integral de desarrollo (Documento Preliminar para Discusión). Presidente del Banco Mundial - 1999. 